\title{
A summary of the research on domestic Design Based Learning
}

\author{
Yujia Tang ${ }^{1, a}$,Xiaofeng Sun ${ }^{2, b}$ \\ ${ }^{1,2}$ School of Hunan University, Changsha 410000, China; \\ a303863665@qq.com, b1624727041@qq.com
}

Keywords: Design based learning; design based learning; theoretical research; practical research

\begin{abstract}
Due to the inherent requirement of social talent gap and educational reform, researchers have begun to expand the research field of design learning in recent years. This article uses the literature analysis method to study the trend, the current situation and the comparative analysis of the theoretical and practical research on the design based learning in China, to sort out the development of China in the field of context, and to provide the necessary theoretical basis for the researchers to study.
\end{abstract}

\section{Introduction}

With the increasing demand of the society for innovative, comprehensive high-quality talent, the international community is trying to find ways to cultivate such talents. Under this background, in recent years, a new learning paradigm has emerged in the field of international education, which is based on the design of learning, and it is also called Design-Based learning(DBL). DBL is a learning method based on a high degree of research of project and a standard. It has improved the tools and techniques to give the students the basic knowledge and skills of each subject. In the same time, students also learn a high level of critical thinking-invention, inference, adaptation and transformation of information, they were gained a deeper understanding of the subject. These technologies have promoted the development of all the students' language learning, and they have enriched the learning experience [1].

\section{The present situation of domestic research based on the design of learning}

Since the publication of the journal articles on DBL in China in 2009, with "design based learning", "based on the design of learning" as the key words to full-text search in CNKI, a total of 50 journals and literatures were obtained. Among them, in the past three years, the number of related literatures was the most. They account for half of the total number of domestic research papers, presenting a blowout state of research results. The figure 1 is a trend chart of domestic papers published. In the chart, the author takes the time as the horizontal coordinate, the number of the paper is the vertical coordinate, and inspects the total number of the annual paper, theoretical research and practical research results three data. According to the chart analysis, use 2013 as a watershed, 2013 years ago, the article, more attention to theoretical research, 2013 after the article more concerned about the practice of research. Especially in the past two years, almost all of the DBL in practical teaching, this shows that the domestic research of the field has now entered the stage of theoretical guidance practice.

In the following paragraph, the author will be based on theoretical and practical research for the classification to divide the articles into two categories: theoretical research, practical research to discussion the papers which in the past 8 years. The theoretical research takes 3 representative articles as the research objects, the practice research takes the discipline as the classification standard, and analyzes the research trends and achievements in the field of DBL. 


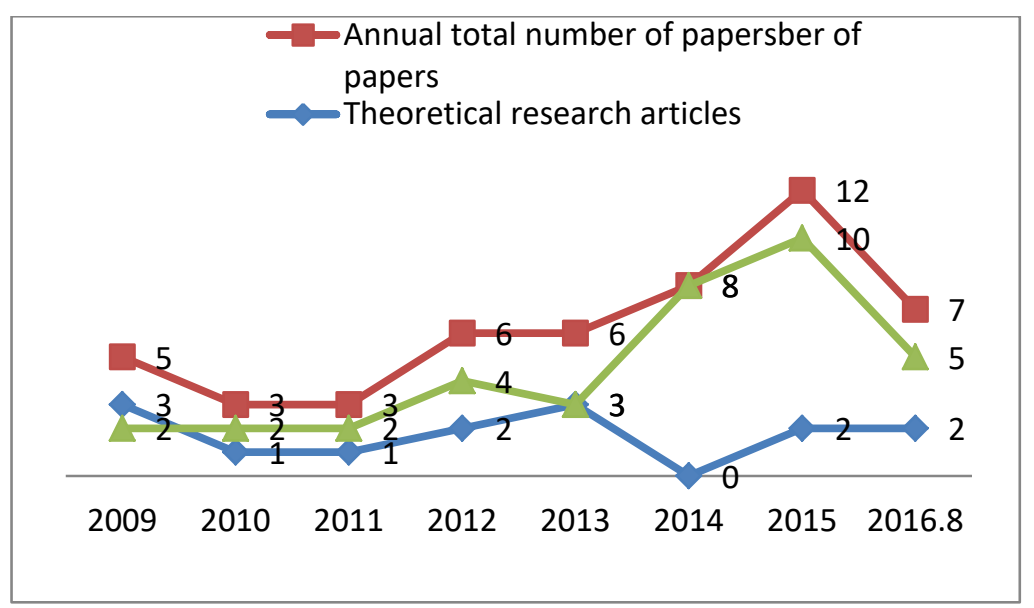

Fig. 1 Domestic papers published trend chart

\section{Domestic theoretical research and analysis}

Design based learning research from the California Polytechnic State University in 1997 by Doreen Nelson professor at the beginning of the K-12 interactive classroom teaching. To officially opened the research in the field of exploration, and professor nelson also therefore is regarded as a founder of design type of learning. Since then, the foreign related research has been ongoing, and produced almost 400 relevant papers and documents.

Domestic scholars began to pay attention to the research field of DBL, and the time point of the literature was recorded in 2009. Professor Kekang He mentioned the DBL in this article 'A comparative analysis of the ways and methods of information technology and curriculum integration at home and abroad'[2]. Although, since 2007, the domestic appeared the articles which are Design-Based research related, the author found that, after the author comparison between Design-Based research and Design-Based learning, although, they are in the same category-design model, and they have a lot of features are similar, but they are very different in the application fields, Design-Based research involves the research field after teaching, and Design-Based learning is to guide teachers and researchers, how to teach the lessons, and knowledge. Go without saying, it will lead to the definition, connotation and mode of the two different, both can't be as one and the same.

Another paper appeared in 2009, the first more comprehensive introduction to the Design-Based Learning's emergence background, definition, characteristics, theoretical basis of the article which is heading for 'Design-Based Learning - a new paradigm of learning' [3]. Through literature analysis, comparative study and case analysis, this paper discusses one of the learning model of DBL- Process model and implementation procedure of Backward Thinking learning. This article affirms that DBL is a novel and effective way of learning, and its theoretical research and application research will become more and more concerned by scholars at home and abroad. The article which's title of 'A review on the research and application of " Design-Based Learning "in foreign countries'[4],the author analyzed several kinds of learning models of DBL, and has made the case analysis to the overseas DBL 's application practice so far. 'Design Based Learning: Let the maker-centered-education landing in Teaching'[5] was combined with the latest, the hottest education concept:maker centered education. Based on the background of maker centered education, this paper analyzes the learning characteristics of DBL. Trying to combine the case to analyze the process of DBL. But the author about this part of the analysis, is not satisfactory. In the article, the author is just a list of cases, not the depth of the combination of creative and DBL.

\section{Domestic practice research and analysis}

In practical application research, since 2009, 'Design-Based learning: Case of teaching- Happy New Year' [6] the first article on the design of learning in the teaching practice of the application of the case, the domestic's articles in DBL of the application have emerged. Next, the author will introduce the typical subjects in the field of the application of more excellent DBL's teaching cases. 


\subsection{Combination of DBL and information technology courses}

The author use the article: 'Programming course teaching practice from the perspective of DBL' as a typical. This author takes the course of "Basic Visual programming" as the practical soil, teachers to carry out teaching practice, summed up the teaching experience, in front of the teaching to sort out the design of learning process[7].And the teaching results show: Experimental design type learning class students learning enthusiasm high, the students improve their performance significantly, experimental design type learning of students in the class of higher learning motivation, student achievement of the upgrade compared to the general class, the effect is more obvious. They are also found that the DBL's invisible advantage which is it can suitable for students of all kinds of abilities. This is also verified in foreign related research. In this case, we can clearly see, DBL has a good effect on cultivating students' enthusiasm, problem solving ability and innovative ability.

\subsection{DBL in the course of Science}

DBL from the origin to the development of the academic community that the most suitable for application in science curriculum, and ' The Design-based learning in general technology teaching in the research on the application of system design and test technology "emergency landing" as an example'[8] is typical of the relevant practice research in China. The author chooses the Nelson Backward thinking operation model which is more easy to use, and the author combines the "emergency landing" technology which is teaching of general technology course to carry on the teaching. The author found that the teaching effect in course of DBL is not very obvious because of the influence of the course difficulty. However, the students' ability to solve problems based on the problem is still improving, and it is better than other learning methods for the improvement of students' abilities. In this practice, we should pay attention to the future research that researchers need to be more cautious about the selection of knowledge and Curriculum.

\subsection{DBL in the experimental course}

'Design-Based Learning: the innovation of experimental teaching model in Colleges and Universities-a case study of multimedia courseware making' [9], this article is based on the design of the experimental course teaching in Colleges and universities. In order to improve the teaching effect and learning efficiency, improve the teaching effect and the teaching practice of Dewey's theory: 'Learning in doing' . The author made a moderate transformation of the model of reverse thinking, joined the demonstration prototype with a brief explanation of the two links, in the end, the learning process of DBL is formed. In the teaching practice, DBL combined with the design of the experimental courses to attract students' attention, but the article on the analysis of the classroom effect of the lack of data support, it appears that the teaching practice is too thin.

\subsection{DBL's practical application of Humanities and Social Sciences Subject}

Study on script creation more biased in favor of the humanistic and social science, script creation and design concept agree without prior without previous consultation, the creators of the script also need to continue to polish it, constantly re-design. In the study of 'Research based on DBL in the film and television script writing practice teaching'[10], the author uses the theory of design learning, combined with the theory of film and television script curriculum, and puts forward the suitable learning process. Students constantly modify in the process of learning and creation, and constantly modify the script, the integration of discipline knowledge, not only improve collaboration capabilities, but also to achieve the integration of Theory and Practice. Researchers have reached the teaching goal of the course, but also for the development of DBL in the field of humanities, the first step to step.

\section{Conclusion}

At present, the research of domestic DBL is still in the stage of absorption and introduction, the work in the field of research is the conceptual, theoretical research and practical research, the evaluation, analysis and research has not yet officially started. A large number of practical research projects provide a great deal of material for future theoretical research, which is the trend of the development of DBL research. 
DBL came into being under the premise of the development of modern education, the practice of research proves that, in the complex learning environment, the DBL can adapt to most of the needs of learners, learning method provides better quality for learners. Learners in the learning process design results, learning and integration of knowledge, training of learners' cooperation and innovation of higher order ability. This learning method will adopt reform direction of current education by more domestic and foreign researchers' attention.

\section{References}

[1] Janet L • Kolodner. Learning by Design: Iterations of Design Challenges for Better Learning of Science Skills [J]. Cognitive Studies, 2002, (9):338-350.

[2] Kekang He. A comparative analysis of the ways and methods of information technology and curriculum integration at home and abroad[J]. China Educational Technology,2009.9(272):8-16.

[3] Youmei Wang, Lu Li. Design-Based Learning - a new paradigm of learning[J]. China Educational Technology,2009,10(273):12-16.

[4] Meifeng Li,Yujie Sun. A review on the research and application of " Design-Based Learning "in foreign countries [J]. Modern educational technology, 2015, 7(24):12-18.

[5] Jun Zhu. Design Based Learning: Let the maker-centered-education landing in Teaching[J]. Information technology education in primary and middle schools, 2016, 7:68-71.

[6] Haifei Wu. Design Based learning: Case of teaching- Happy New Year[J]. Information technology education in primary and middle schools,2009,2:43-45.

[7] Weidong Zheng. Programming course teaching practice from the perspective of Design-Based learning [J]. China Educational Technology.2011,12（299）:98-101.

[8] Xiaohua Deng. The Design-based learning in general technology teaching in the research on the application of system design and test technology "emergency landing" as an example[J]. Research on Curriculum Teaching,2015,4:65-68.

[9] Kejun Zhuang, Baoxun He. Design-Based Learning: the innovation of experimental teaching model in Colleges and Universities -- a case study of multimedia courseware making [J]. Modern educational technology, ,2013,4(23)”110-113.

[10] Zhong Chen. Research based on Design-Based Learning in the film and television script writing practice teaching[J]. University Education,2014,4:119-120. 